\title{
La mediación de conflictos y sus aportaciones al cambio sociocultural de la familia mexicana
}

\author{
Emilia Iglesias Ortuño \\ Universidad de Murcia \\ Cristina Ulloa Espinosa \\ ITESO Universidad Jesuita de Guadalajara
}

\section{Resumen}

El cambio social de la familia mexicana es una constante que acompaña los procesos de transformación social desde el Siglo XX hasta la actualidad. El cambio social en la familia se constata principalmente en la configuración familiar o arreglos familiares; los roles atribuidos a cada miembro, especialmente de género; y en los procesos de vinculación intergeneracional en las unidades de convivencia. Pero, además de estos elementos, se consideran determinantes $y$, en cierto modo característicos de las familias mexicanas, los que refieren a los fenómenos migratorios que han dividido familias; los procesos de traslado del espacio rural a las ciudades; así como la diversidad étnica como elemento garante de las tradiciones culturales a pesar de la continua contradicción con el contexto mexicano más moderno. Todos estos cambios suponen un importante reto para las familias del siglo XXI que deberán esforzarse para buscar estrategias que favorezcan sus interacciones personales $y$ su relación con el contexto cambiante en el que se desarroIlan. Un elemento clave para el mantenimiento del bienestar familiar es la comunicación familiar interna, que servirá de base para la transmisión de necesidades, la demostración del afecto y el vínculo, además de mecanismo para la negociación de conflictos de forma pacífica y constructiva. Para potenciar la comunicación en la familia, los Métodos Alternos de la Solución de Conflictos, en particular la Mediación, se conciben como un espacio neutral donde la familia será asistida por un tercero imparcial para desarrollar, mejorar e implementar sus habilidades comunicativas dirigidas a la toma de decisiones conjunta para la gestión de conflictos internos. Así pues, la Mediación contribuye como recurso externo al desarrollo de la comunicación intrafamiliar para lograr el fortalecimiento familiar y su desarrollo positivo.

Palabras clave

Transformación familiar; Parentalidad; Comunicación; Métodos Alternos de Solución de Conflictos; Mediación

Códigos JEL: D15, I31, K36, N36

\author{
MEDIATION AS AN ALTERNATIVE CONFLICT RESOLUTIONS \\ AND ITS CONTRIBUTION TO MEXICAN FAMILY SOCIAL AND \\ CULTURAL CHANGE
}

\begin{abstract}
Mexican families have experienced constant changes since the last century, mainly related to the composition of families, roles attributed to each member, especially gender roles, and the bonding process among generations coexisting in a living unit. In addition, there are other changes related to largerscale social change phenomena, such as migration from rural to urban areas and migration abroad that has divided families. And the cultural diversity of the country is characterized by contradictions between traditional behaviour and the modern Mexican context. All these changes represent challenges to 21st-century families who must search for strategies to favour personal interactions and their relationship with a changing context. A key element to maintaining family well-being is communication needed to express needs, demonstrate affection and bond, and is essential to peaceful conflict management. In this regard, alternative conflict resolution methods, particularly mediation, are considered helpful mechanisms to enhance communication among family members. Through mediation, an impartial third party assists families to improve and implement their communication abilities aimed at decision making and internal conflict management. Therefore, mediation is a significant resource to develop intrafamily communication and to strengthen healthy family development.
\end{abstract}

Keywords

Family Transformation; Parenting; Communication; Alternative Conflict Resolution; Mediation

JEL codes: D15, I31, K36, N36

Fecha de recepción del original: 3 de agosto de 2021; versión definitiva: 26 de octubre de 2021.

Emilia Iglesias Ortuño, Departamento de Trabajo Social y Servicios Sociales, Universidad de Murcia, España. Tel.: +34 8688830 00; E-mail: ea.iglesiasortuno@um.es; ORCID ID: https://orcid.org/0000-0002-1033-4907.

Cristina Ulloa Espinosa, Departamento de Formación Humana, ITESO Universidad Jesuita de Guadalajara, México. E-mail: cristinau@iteso.mx; ORCID ID: https://orcid.org/0000-0002-4363-7453. 


\section{La mediación de conflictos y sus aportaciones al cambio sociocultural de la familia mexicana}

Emilia Iglesias Ortuño

Universidad de Murcia

Cristina Ulloa Espinosa

ITESO Universidad Jesuita de Guadalajara

1. El cambio sociocultural de la familia mexicana: recorrido histórico

El Consejo Nacional de Población [CONAPO] (2012) define la familia como el ámbito primordial de desarrollo de cualquier ser humano pues constituye la base en la construcción de la identidad, autoestima y esquemas de convivencia social elementales. Como núcleo de la sociedad, la familia es una institución fundamental para la educación y el fomento de los valores humanos esenciales que se transmiten de generación en generación.

La familia contemporánea mexicana, como afirma Esteinou (1996 como se citó en Gutiérrez Capulín, 2016: 223) puede ser considerada como una forma de organización para la gestión de la cotidianidad, así que se pueden comprender las estructuras internas que conforman a la familia para su interacción social y su calidad de vida a partir de las estrategias que el mismo grupo familiar ha venido representando. Esta aportación destaca la forma o estructura como elemento principal para el estudio y comprensión de las dinámicas de la familia moderna, no obstante, Gutiérrez Capulín et al. (2016: 221) determinan que, además de la estructura, el elemento que refiere al parentesco es indispensable para el estudio y análisis de las familias con el fin de visibilizar sus cambios y transformaciones como adaptaciones a través del tiempo [...] en particular, la demografía hace referencia a los tipos de familia, su tamaño (número de integrantes) y el curso de vida familiar, desde la construcción conceptual de la unidad doméstica y del hogar. A partir de esta premisa, los estudios demográficos tienen la finalidad de articular los fenómenos y movimientos sociales que repercuten de manera directa e indirecta en la familia.

A través de los últimos dos siglos, la historia de México ha tenido un marcado elemento de modernidad, apertura, mestizaje y urbanización, hechos que han producido cambios políticos, sociales, culturales y económicos, siendo las familias el eje central donde estos cambios pueden verse materializados en las interacciones, planes de vida, oportunidades, composición y estructura. Así lo perciben Gutiérrez Capulín et al. (2016: 224) cuando explican que con las décadas se generan cambios en las familias, en su estructura y conformación, como también en la forma de pensar y actuar, lo cual se refleja en la población e incide o repercute en factores como la economía, servicios de salud, desarrollo social y en las redes de comunicación personales con sus efectos directos en la población y en las familias mexicanas.

Algunos de los eventos indicados en la Tabla 1 han tenido especial transcendencia en la evolución de las familias mexicana de los últimos dos siglos, destacando la transformación demográfica y la resignificación de los roles de género. Al respecto de la demografía, apunta Welti (2015: 64-65) que el descenso de la fecundidad que se produjo en México ya avanzada la segunda mitad del siglo XX es el proceso más sobresaliente con el cual se completa la transición demográfica, que significó pasar de elevados niveles de natalidad y mortalidad, a un estadio de baja natalidad y mortalidad transitando a través de una etapa opuesta en la cual, al producirse la caída de la mortalidad y mantenerse la natalidad elevada, se produjeron las mayores tasas de incremento de la población de la historia documentada del país, lo que motivó el diseño y puesta en práctica de una política de población para incidir sobre este crecimiento.

A la concepción de la transformación familiar y el componente de género y la resignificación de los roles (en especial los de las mujeres), agregan Gutiérrez Capulín et al. (2016: 224) que los cambios de la familia en México se han dado en un contexto de complejas transformaciones y fenómenos sociopolíticos y económicos, entre otros, que han dejado huella en la estructura y conformación de las familias. Desde la migración de los jefes de familia a la frontera norte (tanto hombres como mujeres), la incorporación de la mujer al mercado laboral, los movimientos sociales de índole laboral y educativo que dieron pie a la formulación de políticas de género instaladas poco a poco en los senos familiares y, por último, la aprobación de la unión de parejas del mismo sexo.

2. El contexto de la familia mexicana del siglo XXI: roles, migración y cultura

Las configuraciones familiares son, como explican Grammont et al. (2004: 358) hogares que se constituyen de manera flexible y temporal a partir de arreglos (acuer- 
Tabla 1: Recorrido sociopolítico en México

\begin{tabular}{|c|c|}
\hline FECHA & HITO HISTÓRICO \\
\hline 1910-1919 & $\begin{array}{l}\text { - Revolución de } 1910 \text { acaecida por un régimen político envejecido que no pudo controlar el empuje de las nuevas } \\
\text { generaciones; la mala administración de justicia y la centralización de poderes; condiciones infrahumanas de cam- } \\
\text { pesinos y obreros; la inexistencia de una justicia social ni participación política. Constituyó un imaginario de trans- } \\
\text { formación social cuyos componentes más emblemáticos han sido el reparto agrario, la educación, la legislación } \\
\text { laboral, entre otros (Reséndiz García, 2011: 124). }\end{array}$ \\
\hline & -Se produce una visibilidad militar de la mujer (alcanzando rangos elevados en el ejército), las Ilamadas Adelitas. \\
\hline
\end{tabular}

1920-1929 - Crisis económica de 1929. “Gran Depresión de México". Significa un quiebre económico de la historia de la migración mexicana en Estados Unidos al generar un escenario migratorio deficitario: retorno a gran escala o repatriación. Se producen reagrupaciones familiares bajo el esquema de la exclusión social, la diferenciación cultural y la pobreza. (Alanís Enciso, 2005: 122).

1930-1939 - Se desarrolla una onda de industrialización con el país que marcó el curso cambiando la producción de una base artesanal a otro tipo industrial. Los hombres se involucraron más en la fuerza de trabajo y las mujeres se concentraron más en la familia (Rendón, 2004).

1940-1949 - El llamado "Milagro Mexicano" cuando México logra un desarrollo económico. Se abre el campo laboral a la mujer y, con esto, se generan modificaciones en el seno familiar (Cabranes Méndez et al., 2019).

1950-1959 -Consolidación del Sufragio universal (con incorporación de la mujer) que otorga a la mujer el carácter de ciudadana sino también le da la oportunidad de la acción social y política (Verea Campos y Hierro Perézcastro, 1998).

1960-1969 - El movimiento estudiantil de 1968 tiene una faceta simbólica con muchas lecturas y se considera una forma de expresar una realidad política dominada por el autoritarismo gubernamental y también en las propias relaciones familiares (Pacheco y Blanco, 2011: 51).

- Se inicia fuertes cambios en las condiciones de crecimiento, ocasionados por los procesos de globalización, a consecuencia de esto, los flujos migratorios cambiaron para adaptarse a las nuevas condiciones prevalecientes (Grammont et al., 2004: 359).

1970-1979 -Se produce una evolución conceptual que desarrolló conceptos nuevos o relativizó otros como los de género, reproducción de las unidades o grupos domésticos, reproducción de la fuerza de trabajo, dinámica comunicativa, entre otros, que atacaban la familia nuclear a pesar de seguir manteniéndola como unidad de análisis (Esteinou, 2010: 66).

1980-1989 - Aumento de las desigualdades como principal riesgo que enfrentaban las familias, hecho que fue contrarrestado por la economía informal (Esteinou, 2006: 77).

- Cambio en la dinámica de las familias nucleares y también en las extensas pues lo hijos eran dejados con los abuelos, lo cual provocó que los lazos familiares y vínculos personales se modificaran y que las relaciones de padres a hijos carecieran de comunicación y se tuviera mejor relación con los abuelos (Gutiérrez Capulín et al., 2016: 224).

1990-1999 - La crisis de 1994 fue una pugna abierta entre Carlos Salinas y Ernesto Zedillo que generó efectos devastadores sobre el bienestar de la población. La economía mexicana se enfrentó a un elevado déficit acompañada de la volátil inversión y la mala supervisión del sistema bancario que se materializó en medidas que impactaban de forma directa en la calidad de vida y responsabilidad fiscal de las familias, comprometiendo el bienestar familiar (Cue Mancera, 2001: 76-79).

2000-2009 - Comparado con la década anterior, en el 2000 el porcentaje de la población casada en México decrece (de 45,8 $\%$ a 44,5 \%), en cambio las uniones libres (cohabitación) aumentan (de 7,4 \% a 10,3 \% (Ramírez Serrano, 2007: 19).

- Se da la pauta de integración de una nueva forma de unión constituida por las parejas del mismo sexo. La controversia acompañó este tipo de unión en los planos legales, sociales y políticos, así como en las ideologías y categorización, pues la idiosincrasia familiar y cultural que se tenía en México recelaba de ese tipo de familias (Gutiérrez Capulín et al., 2016: 226).

- Crisis económica internacional. Una de las más complejas desde la Crisis de 1929. Según INEGI (citado por Campos Covarruvias y Lule Martínez, 2010: 51-52), la tasa de desocupación crece en México tanto en hombres como mujeres. Se producen alzas y caídas del precio del petróleo y los alimentos.

2010-2019 - En diciembre de 2009 la Asamblea del Distrito Federal aprobó las reformas al Código Civil que legaliza el matrimonio entre parejas del mismo sexo: durante 2010 se registraron en el Distrito Federal 380 matrimonios en los cuales los contrayentes son hombres y 309 en los que son mujeres; en 2011 estos eventos fueron de 457 y 345 respectivamente.

- Se conforman las familias monoparentales (16,8 \%monoparentalidad femenina y 2,8\% monoparentalidad masculina), reconstituidas (3,8\%) y los hogares unipersonales (11,1 \%) (López Romo, 2012).

- Para el siglo XXI se requieren políticas públicas familiares en las cuales se exprese claramente la idea de que hoy las personas forman sus familias de acuerdo con sus deseos y opciones individuales, donde se tome en cuenta la participación laboral de las mujeres y los hombres, de manera equitativa (Gutiérrez Capulín et al., 2016: 228).

Fuente: elaboración propia a partir de Alanís Enciso (2005); Campos Covarruvias y Lule Martínez (2010); Cue Mancera (2001); Grammont et al. (2004), Gutiérrez Capulín (2016); López Romo (2012); Pacheco y Blanco (2011); Ramírez Serrano (2007); Reséndiz García (2011); Verea Campos y Hierro Perézcastro (1998). 
dos) entre los miembros de distintas familias con filiación consanguínea o por afinidad (paisanaje, género, edad, padrinazgo, etc.). El concepto nos permite ilustrar la complejidad de lazos que unen a un individuo con el conjunto social en el que vive, así como las alianzas y redes sociales de que dispone. El respecto Esteinou (2006: 81) apunta que, en el pasado, los mexicanos tenían un panorama más claro de lo que era considerado como una buena familia y trataban de orientar su comportamiento con el fin de alcanzarla, mientras que hoy las posibilidades de ser una buena familia se han diferenciado: familias nucleares, extensas, monoparentales, reconstituidas, homosexuales, etc. Todos estos tipos familiares son plausibles y coexisten. Gutiérrez Capulín et al. (2016: 220) reafirman estas ideas al concluir que las familias han cambiado, pues se han modificado los modelos de familia, los tipos de familia y la composición y la integración interna, lo que nos pone frente a la necesidad de replantearla conceptualmente para que se dé cuenta de su diversidad.

Comentan Gutiérrez Capulín et al. (2016: 220) que los fenómenos sociales que se notan en la sociedad mexicana repercuten en la institución familiar y se ven reflejados en cambios demográficos como la reducción de las tasas de mortalidad y de natalidad, la cual causa descensos en el ritmo de crecimiento demográfico. Como consecuencia de estos fenómenos, se generan cambios cualitativos y cuantitativos en las familias, en su estructura y conformación y también en la forma de pensar y actuar. Todo esto se refleja en la población, principalmente en la economía, los servicios de salud y el desarrollo social. Como evidencia de esto, Welti (2015: 55) explica que en años recientes, en el $25 \%$ de los horages (desde el año 2010) el rol de jefe de familia lo ejerce una mujer y puede suponerse que éste porcentaje sigue una tendencia ascendente. Además, el 18,5\% de los hogares familiares son monoparentales y de éstos el 84 $\%$ está encabezado por una mujer, lo que no tiene nada de tradicional y muestra la irrupción de la mujer en un rol que amplía sus responsabilidades y su carga de trabajo en el espacio familiar y fuera de él.

La transformación de la composición de los hogares mexicanos se toma como elemento determinante para sostener la idea de una transformación en la conceptualización de la familia actual. Pero es importante recordar que la forma de las familias mexicanas es consecuencia de una serie de procesos culturales, sociales y estructurales acontecidos por los cambios propios del desarrollo social de los últimos dos siglos. Así García y Oliveira (2004: 298) explican que los cambios estructurales también han dejado sus huellas en las formas de organización de la vida doméstica al contribuir, en cierta medida, a erosionar el modelo familiar del jefe varón como proveedor económico exclusivo de sus familias en diferentes sectores sociales, pero sobre todo en los más pobres. Este aspecto con determinación de roles de género y de producción de recursos ha entrado a confrontar una tradición cultural clásica o tradicional, pero dicha confrontación se considera un paso más de la inevitable, y tal vez necesaria, transformación cultural sobre la familia. Así lo afirma Esteinou (2006: 80) cuando explica que los cambios culturales han actuado no solo para promover resultados positivos sino también como factores desafiantes en la vida familiar.

\subsection{Roles de Género y Parentalidad}

Como se mencionaba anteriormente, uno de los elementos más significativos que han transformado la sociedad mexicana y, por lo tanto, han tenido impacto notorio en la configuración de los hogares y las formas familiares ha sido la evolución de los roles de género. Con respecto a la estructura de roles, explica Esteinou (2006: 86) que podemos decir que la mayoría de las familias sigue un patrón tradicional en el cual las mujeres adultas desempeñan como roles principales el de amas de casa, esposas y madres, y los hombres adultos desempeñan los de ser padres y sostén económico de las familias. Existe también un patrón alternativo, a pesar de que se presenta en menor proporción entre la población, en las familias extensas en donde la estructura de roles es más compleja y la división del trabajo se distribuye en diferentes miembros. Al respecto, expresa Welti (2015: 51) su acuerdo afirmando que la transformación en la condición social de las mujeres es probablemente uno de los procesos que más han impactado la organización familiar. Esta transformación se manifiesta básicamente a través del incremento en el nivel de escolaridad de la población femenina, su participación creciente en el trabajo fuera del hogar y su participación en las actividades político-electorales.

Esta evolución en los roles de género, que afectan a hombres y a mujeres, suponen cambios observables en la configuración familiar. Explica Esteinou (2006: 86) que observamos deslizamientos importantes en la configuración y significado de los roles de madre y ama de casa y del esposo, padre y sostén económico, influenciados por la expectativa y práctica del papel laboral femenino. No obstante $y$, a pesar de las importantes oportunidades que la actualidad brinda al desarrollo libre y consciente de la mujer, el desarrollo de las nuevas masculinidades y las políticas igualitarias entre géneros, se sigue observando un importante sesgo tradicional que no genera el cambio que podría darse e, incluso, favorece la recuperación de la diferenciación tradicional de géneros. Así explican García y Oliveira (2004: 287) dos aspectos destacan por su mayor resistencia al cambio: las concepciones acerca del papel de los varones como responsables principales de la manutención económica de la familia y la menor participación masculina en las actividades reproductivas consideradas como típicamente femeninas (tareas domésticas, en especial). A pesar de la creciente participación económica de las mujeres, ser proveedor sigue teniendo una connotación simbólica muy importante: se asocia con la idea del poder masculino, con la noción de soporte, protección, representación de la familia (esposa, hijos e hijas), responsabilidad y defensa del honor, además, se valora como un indicador de masculinidad pues si los varones no pueden mantener a su familia pierden poder y prestigio.

La encuesta ENDIREH-16 (INEGI, 2016) muestra las opiniones de las ciudadanas mexicanas mayores de 15 años sobre los roles masculinos y femeninos, particularmente sobre las responsabilidades parentales y el cuidado de 
personas enfermas y ancianas. Esta encuesta revela que el $47 \%$ de las mujeres opina que las mujeres que trabajan descuidan a sus hijas e hijos, y que el $69 \%$ de las mujeres opina que las mujeres deben ser igual de responsables que los hombres en traer dinero a casa. Para comprender mejor este dato, que casi podría entenderse como incongruente, Welti (2015: 52) explica que en la mayoría de las familias se sigue un patrón tradicional en el cual la mujer realiza las actividades domésticas del hogar, pero por otro lado hay mujeres casadas que desarrollan una actividad económica fuera del hogar, lo que puede representar desempeñar el papel de madre, ama de casa y complemento o sostén económico del hogar, es decir, no solo la dedicación a la doble jornada sino, en sentido estricto, a la triple jornada. En el caso de los hombres, aunque en la mayoría de las familias siguen siendo el sostén económico principal, si la pareja trabaja, existe la posibilidad de que el varón apoye a la pareja con las actividades propias del hogar y como hecho de reconocimiento éste valorará positivamente los esfuerzos tanto en el trabajo doméstico como en la contribución económica de la mujer por su actividad fuera del hogar.

Estos roles de género, si bien muestran las dinámicas de cuidado así como la actividad económica de la familia, también van a determinar las dinámicas de parentalidad, entendida como las relaciones afectivo-educativas provistas de los padres hacia los hijos. Así lo percibe Esteinou (2004: 264) cuando afirma que la familia nuclear conyugal tradicional como referente simbólico y normativo ha supuesto en gran medida un encadenamiento de roles que ataban al individuo a una posición y a ciertas tareas de la familia; suponía también una división y un ejercicio diferenciado de los roles parentales.

Siguiendo con la evolución generalizada de las dinámicas de roles familiares, a pesar de las comentadas reticencias al cambio, García y Oliveira (2004: 283) han señalado la ocurrencia de posibles cambios en lo que respecta a la atención que los padres prestan a sus hijos(as), en lo que concierne a diversos aspectos relacionados con su cuidado y en la participación que tienen en la recreación. No obstante, y como era de esperar, indica Esteinou (2006: 80) que existen presiones socioculturales para mantener funcionando a la familia que generalmente recaen en las mujeres, trayendo consigo problemas adicionales en la parentalidad, en el cuidado de los adultos mayores y en el manejo de la sobrevivencia cotidiana, y los miembros de la familia tienen que ajustarse emocionalmente a las nuevas condiciones. Esta distribución de roles obedece, como explica Flores Galaz (2011: 150) a dos proposiciones básicas dentro de la familia mexicana; el poder y la supremacía total del padre y por otro lado del amor y el necesario sacrificio absoluto de la madre.

La parentalidad en las sociedades modernas se ha constituido, como explica Esteinou (2004: 265-266), como una actividad en la familia, en la medida en que se espera socialmente que los niños abandonen sus roles productivos para ser atendidos y cuidado en la familia. [...] Se concibe la niñez como una etapa de la vida del individuo que requiere de un espacio y tiempo separados de las dinámicas sociales hostiles más amplias para poder desarrollarse y ser cultivado, ha permeado y ha dado forma poco a poco a un tipo de parentalidad en donde se delimitan figuras y roles sociales especializados para su cuidado, es decir, los progenitores, donde resalta la madre como figura central. Anteriormente, los menores no disponían de esa consideración, hasta el punto de que se llegaba a conductas que actualmente se catalogarían como de riesgo o abusivas, que además condicionaban los patrones educativos (más autoritarios), afectivos (más distantes) e inclusivos (más jerárquicos). Pero a pesar de esto, las generaciones pasadas criadas en el siglo XX pudieron evolucionar y al respecto de este cambio, indica Esteinou (2004: 279) que la familia ha sido una orientación de valor tan fuerte que en sí misma compensó los rasgos autoritarios, pero pudo hacerlo porque brindaba un fuerte sentido de seguridad (material, pero sobre todo simbólica) garantizada, que no tenía que ser construida a través de la expresión y exposición continua de sentimientos e intereses individuales. La seguridad que brindaba radicaba en que las relaciones parentales y la familia estaban siembre ahí y se podría en cualquier momento contar con ellos; no eran cuestionables.

Como consecuencia de este recorrido, García y Oliveira (2004: 283) afirman que la parentalidad en México urbano de finales del siglo XX puede comprender muy diferenciadas y complejas dimensiones: la propia decisión de tener o cuándo tener hijos e hijas; la manutención económica y la relación de autoridad; el cuidado infantil en lo que respecta a la alimentación, la higiene y la salud; la crianza y los aspectos relacionados con la disciplina y la transmisión de conocimientos; y también el afecto, la comunicación y la cercanía entre padres e hijos. Estas dimensiones podrían entenderse como situaciones de conflicto que tratar o abordar desde la mediación para lograr superar la crisis que supone para la unidad familiar conseguir, además, un efecto positivo para el desarrollo familiar y su trayectoria futura.

\subsection{Demografía y Migración}

Los movimientos migratorios son aquellos que implican traslados o desplazamientos de grupos humanos diversos y que implicarán cambios de residencia así como la adaptación a modelos de socialización, económicos y culturales diferentes a los de origen. Las motivaciones son diversas y los grupos que se movilizan también, por lo que la migración es un fenómeno complejo que despierta el interés de las investigaciones sociales por sus múltiples consecuencias poblacionales. Como fenómeno de estudio, la migración es compleja pues, como afirman Chande et al. (1979: 185), los movimientos migratorios se manifiestan fuera de delimitaciones naturales que permitan un mejor cotejo numérico de ellos y se sujetan a fluctuaciones de mayor carácter errático. La razón estriba en el hecho de que las corrientes migratorias tienen como motivo ingredientes de índole socioeconómico, con toda la complejidad que esto implica. [...] Tales peculiaridades presentan 
una dificultad inmediata cuando se intenta el estudio del fenómeno: la carencia de información estadística y la dificultad para generar datos. Sobre la complejidad y variabilidad de los fenómenos migratorios, agregan Grammont et al. (2004: 379) que los ciclos migratorios se hacen cada vez más complejos porque dependen de numerosos factores (ciclos de vida, estrategias familiares, redes sociales, políticas migratorias, etc.) Hoy en día, la migración no supone el desplazamiento de individuos del lugar de origen hacia un solo lugar de destino. [...]Los lugares de destino se vuelven aleatorios, dependiendo de la demanda en los mercados de trabajo, pero también de las redes sociales con que cuenta el individuo, que le permiten acceder a dichos mercados, así como encontrar un lugar en el cual establecerse.

Sobre la migración en México, Blejer et al. (1977) explican que durante el Siglo XX la migración mexicana ha tendido a fluctuar en lo que a primera vista parece ser una respuesta particular directa a las condiciones económicas de los Estados Unidos, dentro del contexto de una política tolerante de inmigración. La migración hacia Estados Unidos ha crecido de manera sorprendente. Se estima que actualmente hay alrededor de ocho millones de mexicanos instalados en ese país. Estos migrantes trabajan en todas las actividades económicas, aunque la agricultura sigue siendo una de sus principales fuentes de empleo $(23,8 \%)$ seguida de la industria (22,2\%) y el $15 \%$ en los servicios públicos (Grammont et al., 2004: 359-365). En este sentido, Chande et al. (1979: 185) afirman que una migración puede ser una decisión individual, o familiar o darse de manera masiva, puede ser en busca de una mejor oportunidad económica o puede ser producto de una guerra o de una persecución política religiosa. Concuerda Cornia (1987) afirmando que el conjunto de acciones o tácticas de supervivencia de las familias giran en torno a tres elementos: la generación o procuración de recursos; la eficacia de los recursos internos; las estrategias de extensión familiar (redes) y migración. La migración se ha vuelto una estrategia importante que las familias mexicanas, como afirma Esteinou (2006: 80 ) y ha sido positiva para obtener mayores recursos económicos. Pero genera también mucho estrés en las familias, dado que uno o más miembros pasan largos período fuera de la casa, el riesgo de desintegración familiar está presente, en el sentido de que puede alterar sustancialmente la cohesión, la interacción intersubjetiva y los procesos de comunicación vinculante.

Los estudios sobre los procesos migratorios que implican a las familias mexicanas son de diversa índole y se realizan desde diversas ópticas disciplinarias puesto que los movimientos migratorios son fenómenos multicausales y de impacto diverso. Al respecto, agregan Grammont et al. (2004: 359) que el estudio de las migraciones ilustra la manera en que los ciclos migratorios movilizan un conjunto de relaciones y redes, generando una diversidad de configuraciones familiares que permiten a los individuos establecer puentes entre el lugar de residencia (o de origen) y los distintos espacios de trabajo que surgen a lo largo de los ciclos migratorios. Sobre las formas familiares, agrega Welti (2015: 171) que el crecimiento de las familias en las cuales una mujer es la jefa, se debe a la disolución de uniones entre las mujeres en edades jóvenes, en una etapa del matrimonio en la cual estas mujeres son madres con hijos pequeños. Además de esta situación, se observa un aumento de las madres solteras que son jefas de familia y finalmente un incremento asociado a la emigración de los hombres que previamente eran los jefes de familia.

Como principales impactos de los fenómenos migratorios, se puede destacar el conjunto de consecuencias al interior de las familias al verse afectado el conjunto de dinámicas, de distribución de roles y responsabilidades, así como las formas de interacción de los miembros. Si bien las migraciones tienden a separar a las familias, Grammont et al. (2004: 359-360) indican que la separación geográfica no significa un rompimiento de los lazos familiares. A pesar de la distancia, los vínculos se preservan, se transforman y, a menudo se refuerzan. A la vez, esta tendencia que separa a los miembros consanguíneos de una familia a menudo encuentra su contrapunto en el reagrupamiento de miembros unidos por lazos de afinidad o simbólicos, lo que da lugar a un nuevo tipo de configuraciones que se adaptan a las situaciones migratorias. Son los denominados hogares transnacionales. Otra de las consecuencias al interior de las familias tiene que ver con las relaciones de la propia unidad familiar con su entorno y su adaptabilidad o desarrollo para el bienestar e integración social. Con respecto a este tema Esteinou (2006: 78) explica que demás de los cambios en la organización y estructuración de roles, las tendencias económicas han tenido como resultado un problema importante de pobreza, tanto en las áreas urbanas como rurales, a pesar de que es más profunda en las últimas.

Los procesos de pérdida de cohesión familiar, el deterioro de los vínculos interpersonales y la presencia de aquellos que emigran en el desarrollo cotidiano de la dinámica familiar pueden ser temas abordables desde mediación pues, con esta alternativa, se puede trazar un plan de convivencia que supere la distancia física, pero permita garantizar la cercanía emocional e implicación familiar.

\subsection{Cultura y formación académica}

La cultura puede entenderse como el conjunto de rasgos característicos que determinan y distinguen una sociedad concreta en una determinada época. Los rasgos que determinan la cultura incluyen elementos relacionados con el saber, los valores, la política, las artes, la gastronomía, las normas sociales y las formas de interacción interpersonal micro y macro, entre otros elementos. Sobre la cultura y su incidencia en la idiosincrasia social, Gonzalbo Aizpuru (1998: 392) remarca que todavía hay quien considera que existen actos espontáneos, irreflexivos o tradicionales, en los que no intervienen determinaciones culturales o prejuicios sociales. Difícilmente podrán encontrarse ejemplos de tales impulsos naturales en las manifestaciones de lo cotidiano reconocidas por su carácter rutinario y colectivo [...] Las experiencias cotidianas proporcionan una refe- 
rencia básica para contrastar ideologías y prácticas, y para definir problemas relacionados con la confrontación entre grupos sociales, con la permanente pugna entre tradición y modernidad y con la formación de una conciencia de identidad.

De estos elementos se destaca el marcado componente simbólico, subjetivo o apreciativo de las manifestaciones de la cultura en las interacciones sociales que, como explica Flores Galaz (2011: 149) se trata de un ecosistema humano que, más allá de las variables biológicas, incluye un poderoso ecosistema subjetivo, es decir, la forma como el individuo y los diversos grupos perciben su funcionamiento, el del ecosistema objetivo y, además, variables antropológicas, sociales, estructurales y económicas objetivas. El factor más importante para el desarrollo del individuo es precisamente la percepción que tiene de sí mismo, la percepción que tiene el grupo y el ecosistema entero. Con relación a estas percepciones y concepciones internas y externas que se materializan en la construcción de las relaciones sociales, explica Esteinou (2006: 81) que hay una multiplicación de los significados sociales y culturales en la vida familiar, lo cual hace más difícil para los individuos y las familias seguir los estándares sociales y culturales vigentes para orientar su comportamiento, en contraste con los relativamente pocos estándares sociales y culturales que orientaban antes su comportamiento.

Retomando el componente temporal, la cultura mexicana ha evolucionado de la misma forma en que los grupos sociales se han adaptado a los avances y logros del conjunto de la humanidad. La cultura mexicana y su evolución en los últimos dos siglos, materializada en los cambios de las dinámicas culturales, se estudian desglosando sus componentes principales en dimensiones relacionadas con la autopercepción, las relaciones interpersonales o las relaciones con las instituciones sociales. Sobre estos avances, Welti (2015: 53) explica que hace cuatro décadas las familias mexicanas tenían más estabilidad, además de una cultura comunitaria fuerte y las tradiciones se reproducían a lo largo de las generaciones, debido en gran parte a la presencia de los pueblos indígenas. Así, el proceso de modernización impacta a la vida social y cultural y, como explica Esteinou (2004: 259) que en las últimas décadas el país ha registrado un proceso de modernización no solo en el plano económico y demográfico, sino también en el nivel sociocultural. Como consecuencia, incorporan Gutiérrez Capulín et al. (2016: 227) que para finales del siglo XX, el concepto de familia ha sufrido transformaciones radicales durante las últimas décadas, es decir, que el concepto de la década de los sesenta ya no encaja dentro de la familia del siglo XXI, donde la idea de que el hombre es quien da el sustento en el hogar y la mujer es solo ama de casa, se queda en el pasado. Además, la pobreza, la migración y el cambio cultural son algunos de los desafíos externos y que tienen que ser enfrentados por las familias.

La secularización, la diferenciación simbólica, los cambios en la estructura de roles y los cambios entre generaciones son aquellos que enfrentan las familias y que provienen de su configuración interna. El resultado de esto es que las familias se enfrentan a importantes desafíos a resolver que requieren cambios, adaptaciones y transformación de simbologías y configuración interna para la adaptabilidad a las configuraciones de su contexto social externo en continua evolución.

Otro de los principales desafíos que enfrenta la familia mexicana es el relativo a la composición familiar que estará determinada, no solo por la planificación familiar y la creencia cultural presente en cuanto al modelo óptimo de familia, sino al componente de fecundidad, relacionado con la toma de decisiones sobre la concepción a través de una serie de elementos de programación voluntaria a los que se suman los elementos biológicos y, en muchos casos, condicionantes de la misma. La reconversión mundial de los sistemas productivos se traduce para la juventud en un bloqueo del acceso al mercado laboral y, por tanto, también de la emancipación y la formación de familia propia. Simultáneamente, las generaciones de jóvenes protagonizaron el salto del nivel de estudios hasta alcanzar los estudios superiores, algo sin precedentes; las mujeres, además de sumarse a esta eclosión, rebasan a los hombres por primera vez en esa dedicación. Al respecto, Covarrubias Terán y Gómez Herrera (2012: 248) explican que actualmente en México han ocurrido grandes avances en la preparación académica de los padres y de las madres de clase media; consecuentemente se han modificado las relaciones sociales, la dinámica de las relaciones intrafamiliares y se ha favorecido la inserción laboral de las mujeres. Regularmente los padres y madres contemporáneos buscan superarse cultural y académicamente con base en la creencia de que la preparación parental será determinante para la acción educativo-afectiva y socializadora que se ejecutará en la familia.

Finalmente, pero con importancia crucial, Pérez Díaz y Abellán García (2018: 18) explican que el efecto calendario ha contribuido al control de la natalidad (reducción) con factores novedosos de orden diverso. El retraso en el nacimiento del primer hijo aumenta la probabilidad de que finalmente no se tenga ninguno $y$, en efecto, es previsible la infecundidad entre las generaciones que actualmente están en edad de tener hijos. A modo de explicación concreta de este fenómeno, se incorporan las afirmaciones de Covarrubias Terán y Gómez Herrera (2012: 258) que puntualizan que en la primera mitad del siglo XX las mujeres tenían su primer hijo/a entre los 12 y 16 años; a partir de la década de los 60 lo tenían entre los 20 y 25 años. Actualmente, y sobre todo cuando las mujeres tienen el nivel educativo elevado y se han incorporado a las labores productivas, tienden a postergar el nacimiento de su primer hijo/a hasta después de los 30. De este análisis se determina que el factor calendario es determinante en los procesos de natalidad y demografía de México, siendo la variable académica una de las más determinantes pues supone posponer la consideración de independencia social y económica a un proceso educativo cada vez más largo.

A modo de resumen de lo estudiado en este recorrido histórico sobre las transformaciones de las familias mexicanas, queda de manifiesto que cada transformación ha necesitado una adaptación o asimilación que, hasta que se ha conquistado, ha requerido un proceso de cambio. Los cambios sociales, más especialmente cuando se experimentan desde lo microsocial y las relaciones interpersonales, pueden generar procesos de crisis, entendida ésta como la necesidad de enfrentarse a una situación que no 
está en el repertorio habitual de problemas, por lo que la persona o unidad familiar queda desorientada $y$, en muchos casos, afectada y deteriorada. Por todo esto, los procesos de gestión de esas crisis de adaptación a los cambios sociales y culturales que se traducen en las dinámicas interpersonales deben estar acompañados de métodos o estrategias que aporten posibilidades reales para un afrontamiento y gestión que brinde resultados positivos para los miembros de la familia.

3. La Mediación como método alternativo de gestión de conflictos familiares.

Los Métodos alternos de solución de conflictos consisten, en palabras de Valdo Grajales (2006: 377) en diversos procedimientos mediante los cuales las personas pueden resolver sus controversias, a esta idea añaden Márquez y Villa (2013: 1587) que los métodos alternos son diferentes a los jurisdiccionales y tienen como objetivo resolver conflictos suscitados entre partes con un problema de intereses, dentro de ellos se encuentran la mediación, la conciliación y el arbitraje.

Los Métodos Alternativos de solución de conflictos ingresan formalmente en México en la década de los 90, como explican Gorjón Gómez y Sáenz López (2013: 149), mediante el Modelo de Arbitraje para el Derecho Mercantil Internacional de la Comisión de las Naciones Unidas [CNUDMI]. Este modelo se consideró la iniciativa para la incorporación paulatina del Arbitraje a los códigos Civiles mexicanos a partir de 1995. Así mismo, este hito transciende en el sistema judicial mexicano otorgándole un carácter internacional mediante la asunción de principios mundiales y referencias europeas en materia de Justicia Alternativa. En este sentido incorpora Rosales (2018: 233) que las reformas constitucionales decretadas el 18 de junio de 2008 sobre el Sistema Penal Acusatorio han marcado sin duda el inicio de una serie de novedades del proceso judicial.

El artículo 17 constitucional prevé los mecanismos alternativos de solución de conflictos que garantizan la reparación del daño, siendo la justicia restaurativa, mediación, conciliación y arbitraje las principales formas de negociación o toma de decisiones que posibilitan a los operadores del Derecho la aplicación de un debido proceso. Como consecuencia de todo esto, en la actualidad México cuenta con 30 normativas estatales específicas sobre Métodos Alternos relacionadas con las competencias en Justicia Alternativa, familia y sociedad, todas ellas en el marco de una ley Federal que centraliza las competencias penales denominada Ley DOP 29/12/2014, Nacional de Mecanismos Alternativos de solución de controversias en Materia Penal.

Los Métodos Alternos se conciben como un esquema de gestión de conflictos tendente a la composición pacífica de los mismos y a la reparación del daño o consecuen- cias de las discrepancias entre las partes. Así mismo se conciben como estrategia de soporte para un sistema jurídico en constante demanda que requiere vías de distribución de trabajo que garanticen soluciones efectivas y eficaces a la ciudadanía. No obstante, este esquema emergente debe revisarse y evaluarse para determinar sus áreas de oportunidad y sus líneas de mejora y adaptación a las necesidades sociales. En este sentido de transformación y mejora Redorta Lorente (2009: 28) explica que en el marco del VI Congreso Europeo de Ley y Psicología, celebrado en BarceIona en 1994, se confirmó la idea de que el modelo judicial es agónico de cara al Siglo XXI pues presentar la Justicia como un combate pasaría a no tener ningún sentido y se hace preciso retornas a las fuentes naturales de resolución de los conflictos. Con intención de una renovación de estos sistemas alternativos para ajustarlos a las necesidades de la institución judicial, pero, también, a las necesidades y potencialidades sociales, en el año 2002 la Comisión Europea hace público el Libro Verde sobre modalidades alternativas de solución de conflictos en el ámbito del derecho civil y mercantil [COM (2002) 196]. El objetivo de este manual es hacer balance de la eficacia, pertinencia y procuración de los Métodos Alternos para poder ofrecer una renovación consensuada acorde a las necesidades sociales y en previsión de la extensión de la justicia alternativa. De este documento se extrae como principal idea que la implantación de los sistemas alternativos se han de marcar como objetivo prioritario la recuperación del poder de las partes en procesos extrajudiciales o bien facilitando el acceso a la justicia y a una solución justa y eficaz en un plazo razonable de tiempo. De todo esto se deriva la necesidad de que la opción de los métodos alterno sea fácil para los ciudadanos y no esté entorpecida por requisitos burocráticos. Especialmente la mediación se basa en sustituir la estrategia del enfrentamiento por la de la colaboración por lo que, tal como se destaca en el preámbulo del Libro Verde de la Comisión Europea, es un instrumento eficaz para la paz social, especialmente cuando las partes han de seguir conviviendo o relacionándose de algún modo.

Lo más significativo de la incursión de los Métodos Alternativos como elemento integrado al Sistema Jurídico tradicional es la proliferación de los mismos a nivel extrajudicial. En este sentido, indica Redorta Lorente (2009: 29) que el conflicto es una realidad muy multidisciplinar $y$ compleja, sin embargo, tratamos de resolverlo desde una única visión disciplinar. Además, añade que hemos aprendido a resolver los conflictos desde la confrontación, pero no es seguro que los resolvamos pues lo que en un momento fue un medio para equilibrar derechos y establecer justicia, tiende a convertirse en un conflicto de poder, en una competición inacabable que desgasta a todos. Como consecuencia de todo esto, las instituciones públicas como únicos representantes del interés general se van a relativizar, es decir, perderán protagonismos las instituciones públicas como referentes más importantes en la regulación de los conflictos Redorta Lorente (2009: 30) siendo la ciudadanía en el espacio privado quien deberá asumir la responsabilidad de la autogestión pacífica de sus propios conflictos o hacer uso de mecanismos alternativos al sistema judicial y, además, externos al mismo. 


\subsection{La mediación como concepto}

La mediación es una estrategia de gestión de conflictos interpersonales que parte de la premisa de que todo conflicto puede tener una forma positiva de ser gestionado, además de la convicción de que en cada situación de conflicto, si éste se gestiona de forma eficaz, se produce una transformación en las habilidades de la persona o personas implicadas que contribuyen a una concepción pacífica de las interacciones sociales.

Con relación a la concepción positiva de los conflictos afirma Alzate Sáez de Heredia (2007: 41) que para romper el patrón que nos mantiene en conflicto y para resolverlo de una manera productiva, primero necesitamos tomar conciencia de las creencias y respuestas que perpetúan nuestra conducta negativa. La reflexión es un paso vital para lograr esta toma de conciencia y se obtiene dando un paso hacia adelante en el conocimiento de nosotros mismos y de nuestras opciones sabiendo que, aunque el conflicto es inevitable, no tiene por qué ser destructivo.

La mediación se define, en palabras de Suáres (1996: 50) como un proceso formalizado en varias etapas que tiene lugar en un contexto más flexible que otros modelos de gestión para la resolución de conflictos, en el que un tercero, el mediador, actúa para ayudar a las partes a alcanzar un acuerdo y la decisión de iniciar este proceso es voluntaria. Durante el proceso, el mediador desempeña el rol de facilitador de la comunicación entre las partes y no es árbitro ni juez, ya que no es él quien resuelve, en definitiva, sino que lo hacen las partes mismas. Los mediadores son los defensores de un proceso equitativo, y no de un determinado resultado. Carecen de poder de decisión autorizado, esto es lo que los distingue, básicamente, del juez o del árbitro (Moore, 1995: 49)

El proceso de mediación es voluntario porque, como explica Moore (1995: 72-78) las personas ingresan al mismo por propia decisión, ellas mismas determinan cual es la información que transmiten y cual ocultan, deciden si llegan o no a un acuerdo y se retiran cuando ellas así lo estimen, en el mismo instante en que dejen de sentirse cómodos. Nadie está obligado a permanecer en contra de su voluntad. En este sentido, incorporan Soleto Muñoz y Otero Parga (2007: 19) que la mediación no pretende sustituir la actividad judicial, ni enmendarla, únicamente pretende ofrecer una vía alternativa a la judicial, en la creencia de la pluralidad que debe regir el análisis de la experiencia judicial.

La mediación familiar, como área de especialización, tiene como objeto, como explica Rondón García (2012: 32) lograr que los diferentes miembros de la familia acuerden entre sí llevar a cabo un proceso de resolución de conflictos a partir de la intervención guiada de un profesional quien ayudará de una manera neutral a cada uno a definir el problema tal y como ellos mismos lo ven, a entender las opiniones e intereses de los demás, a buscar todos juntos soluciones válidas y duraderas en el tiempo. A través de los propios implicados en la resolución de sus conflictos, el mediador hace que cada uno de ellos tome conciencia de su protagonismo activo no solo en el momento actual, sino también en el futuro.

El desarrollo de la mediación en México, como el de los métodos alternos, es un hecho y tiene remarcable transcendencia social. Así Gorjón Gómez y Vázquez Gutiérrez (2015: 25) la mediación, como forma de resolver los conflictos, cuenta cada día con más ámbitos de actuación y con un mayor número de factores de impacto sociales y jurídicos. La mediación familiar es uno de los ámbitos de aplicación de mayor éxito y a su vez de mayor dificultad operativa pues no solo se trabaja con el conflicto como materia dependiente de la relación entre las partes, sino que además el mediador deberá tomar en cuenta el rol familiar existente y con ello procurar durante todo el procedimiento que además de un acuerdo que finalice el conflicto, se logre el restablecimiento de la relación quebrantada o la comunicación alterada que propició la situación conflictiva.

3.2. La comunicación en la familia y su relevancia en el proceso mediador

Paca comprender el significado del proceso comunicativo, así como sus componentes, se puede recurrir a la definición de Park (1938: 189) que la define como una forma de interacción que permite que las personas intercambien sus puntos de vista, consensuen y lleguen a entablar, incluso, una posición moral respecto al mundo. Por medio de la interacción obtienen una orientación para ver la realidad, así pues, Comunicación es interacción. De esta definición destaca el componente interactivo en las relaciones sociales, de gran relevancia para Garza Guzmán (2014: 320) pues explica que el estudio de la acción social es especialmente importante para la comprensión de la comunicación interpersonal pues deja claro el carácter subjetivo e interactivo de la actividad social y, por lo tanto, de la comunicación interpersonal. A este respecto, agrega Rizo (2021: 3) que la comunicación interpersonal se define como el encuentro cara a cara entre dos personas que sostienen una relación de interdependencia a través de un intercambio de mensajes que proceden de señales tanto verbales como no verbales. Así, la comunicación como fundamento de la interacción social, es el principio básico de las relaciones sociales. Es, pues, un proceso social articulado en torno al fenómeno de compartir, de poner en común y de vincular. En el proceso de comunicación interpersonal, los sujetos proyectan sus subjetividades y modelos del mundo, interactúan desde sus lugares y la construcción de sus sentidos.

La comunicación es una actividad de vinculación social con un fin interactivo y un marcado componente subjetivo donde las personas implicadas manifiestan su percepción y opinión sobre su contexto. Incorpora Villalobos (1998: 
Tabla 2: Patrones comunicativos de la familia

\begin{tabular}{|c|c|}
\hline Patrón & Características \\
\hline $\begin{array}{l}\text { Comunicación } \\
\text { orientada a la con- } \\
\text { versación }\end{array}$ & $\begin{array}{l}\text { Lo explican los autores destacando como componente principal el grado en el que las familias crean un } \\
\text { clima donde los miembros de la familia se atreven a participar en interacciones abiertas y de temáticas } \\
\text { variadas. } \\
\text { En las familias con este patrón, los miembros interactúan de forma libre, frecuente y espontánea con po- } \\
\text { cas limitaciones en cuanto al tiempo disponible de conversación o los temas a tratar. Estas familias pasan } \\
\text { mucho tiempo interactuando unos con otros además de compartir actividades individuales, pensamien- } \\
\text { tos y sentimientos. Las familias que tienen menos desarrollado este patrón de comunicación ven reduci- } \\
\text { dos los momentos de interacción y solo se habla de determinados temas de interés conjunto. Hay menos } \\
\text { conversación sobre pensamientos privados o personales, sentimientos y actividades. } \\
\text { Para este patrón es esencial una comunicación habitual y abierta. La toma de decisiones incluye a todos } \\
\text { los miembros para aportar valoraciones y se admiten negociaciones. Las familias emplean la comunica- } \\
\text { ción como elemento de intercambio de ideas, así como elemento para educar a los menores y proveer } \\
\text { estrategias de socialización. }\end{array}$ \\
\hline $\begin{array}{l}\text { Comunicación } \\
\text { orientada a la con- } \\
\text { formidad }\end{array}$ & $\begin{array}{l}\text { Lo explican los autores destacando como componente principal el grado en el que las familias enfatizan } \\
\text { un clima de homogeneidad en las actitudes, valores y creencias de sus miembros. } \\
\text { En las familias con este patrón, la interacción de los miembros enfocadas en la uniformidad de las actitu- } \\
\text { des y están enfocadas en la harmonía, la evitación de conflictos y la interdependencia de los miembros } \\
\text { de la familia. Las relaciones intergeneracionales se realizan con base en la obediencia de los hijos hacia } \\
\text { los padres. Las familias que tienen menos desarrollado este patrón de comunicación se caracterizan por la } \\
\text { conformidad con la heterogeneidad de pensamiento y en la individualidad de los integrantes. } \\
\text { Para este patrón está más presente en lo que se conoce como formas familiares tradicionales. Las familias } \\
\text { están cohesionadas y regidas por un régimen jerárquico y se comparten los recursos individuales en el } \\
\text { conjunto de integrantes. Las familias consideran que los horarios de cada miembro se pueden planificar } \\
\text { en función del interés general, además, los intereses generales de la familia van a prevalecer por encima } \\
\text { de los intereses individuales. }\end{array}$ \\
\hline
\end{tabular}

Fuente: elaboración propia a partir de Koerner y Fitzpatrick (2002: 85-87).

19) que la comunicación se entiende como un acto en el que cada persona interviene en el diálogo a partir de sus intereses, de su acervo cultural, de su personalidad, con un lenguaje que le sirve en su contexto social y le favorece la integración. Incorpora, además, su propia concepción del mundo y de la vida, todo ello interrelacionando la cultura, la sociedad y la personalidad.

A partir de estas definiciones se constata que la comunicación es un proceso de interacción social en el que las personas implicadas comparten opiniones y valoraciones sobre elementos de su contexto, todo ello bajo un marcado componente cultural y apreciativo propio de un determinado lugar. La familia, como principal espacio socializador, es un espacio de reproducción de comunicación (hábitos, patrones y subjetividades) que, además de informar, provee de aspectos históricos pues la comunicación es el medio para la construcción de la realidad familiar en su contexto. Al efecto, afirman Whitchurch y Dickson (1987: 693) que la realidad social de la familia es construida por sus integrantes a través de sus interacciones interpersonales creando y sosteniendo la identidad familiar propia, todo ello con base en procesos de comunicación (ideas, valores, proyectos, afectos) siendo la comunicación el ele- mento esencial para que la familia cree su propio mundo social. En este sentido, incorpora Díaz Argüello (2011: 69) que el sistema humano familiar genera lenguaje y significado y en este proceso vive en un constante devenir de intersubjetividad, la cual es vivida gracias a los permanentes actos comunicativos o diálogos y todo eso dentro de una estructura sociocultural.

Los patrones comunicativos de las familias determinarán las estrategias comunicativas familiares contemplando, entre otros aspectos, la eficacia, la frecuencia y el objetivo de la comunicación. Koerner y Fitzpatrick (2002: 85-87) identifican dos patrones de comunicación claros: el patrón de comunicación orientada a la conversación y el patrón de comunicación orientada a la conformidad.

Del análisis de estos dos patrones se conciben dos estrategias antagónicas en el establecimiento de las relaciones interpersonales a partir de la comunicación entre los miembros de la familia. Lo destacable es que el modelo familiar parece ser el factor que estipula las estrategias comunicativas que determinará, en primera instancia, los roles familiares que determinarán el grado en que cada miembro de la familia participará en los procesos comunicativos. Las familias con un patrón orientado a la con- 
formidad se identifican como familias tradicionales con componente jerárquico que otorga validez al discurso de los adultos y requiere obediencia y conformidad por parte de los menores de edad. Mientras que, en la familia con un patrón orientado a la conversación, se identifican como familias modernas con componente inclusivo que otorga la misma validez a los discursos de todos los miembros y se requiere comprensión por parte de todos. A pesar de que, a priori, los dos métodos son válidos o podrían ser eficaces pues responden a las características internas de la familia que lo ejecuta, las transformaciones sociales anteriormente analizadas muestran una tendencia hacia la transformación del imaginario familiar que abandona el ideal tradicional de la familia compacta, unida, afín y jerárquica hacia una concepción dinámica, diversa, activa y que invierte tiempo en los procesos de socialización interna de sus miembros, por el puro interés de esa socialización. La socialización interna es una forma de comunicar afectos que genera, además de una historia familiar amplia, inclusiva, honesta y transcendental, genera bienestar a los miembros de la familia, cuestión que retoma Díaz Argüello (2011: 69) cuando afirma que la interacción basada en un lenguaje dotado de buen trato lleva a construir significados compartidos relacionados con el hecho de tratar a otro y ser tratado por otro, desde y para el bienestar.

Del estudio de estos dos patrones, es destacable en este trabajo, el análisis de las estrategias de abordaje de los conflictos intrafamiliares. Las familias con patrones de comunicación orientados a la conversación consideran la comunicación como vía para la comprensión de los conflictos, la validación de posturas, el aporte de soluciones y la negociación de estrategias de interacción futuras. Por el contrario, las familias con patrones de comunicación orientados a la conformidad tienden a evitar la confrontación que se genera en un proceso de conflicto y recurre, en todo caso, a la autoridad o jerarquía para la resolución de los mismos. Este hecho se relaciona con la concepción actual del conflicto como oportunidad de cambio frente a la concepción tradicional que le atribuye sesgo negativo y que recomienda la evitación como mejor estrategia de gestión.

Moore (1995: 9) indica que la mediación es una negociación asistida por un tercero aceptable, es decir, la mediación es esencialmente una negociación entre partes en conflicto, pero que requiere de un tercero conocedor de los métodos y técnicas eficaces en negociación. A esta idea incorpora Rondón García (2012: 32-33) que uno de los componentes esenciales de la mediación es que tiene como función final la de establecer o restablecer una comunicación inexistente o deteriorada [...], es decir, la mediación tiene por objeto dar respuesta a las necesidades de cada uno a través de un proceso de reflexión y toma de decisiones facilitando a partir de la creación de un espacio compartido de escucha, respeto, confianza y compromiso.

De las ideas de Grover et al. (1996), recogemos que cuando la comunicación entre las partes se vuelve tensa o inexistente, aumenta la intensidad del conflicto, por esto el mediador busca mejorar la capacidad de las partes para comunicarse y explorar las actitudes y posiciones mutuas. Sobre este aspecto incorpora Rondón García (2021:54) que uno de los elementos que determina la naturaleza del perfil mediador es que la persona mediadora debe equilibrar a las dos partes, aunque está de parte de todos, potenciando la simetría del proceso comunicativo. Así pues, como idea clarificadora se puede determinar que la función del mediador es la de facilitador de la comunicación entre las partes para que no se produzcan interferencias que dificulten el entendimiento en las comunicaciones, posibilitando la libre expresión de ideas y el reconocimiento y validación de las mismas.

De todo esto, se destaca la labor catalizadora de la persona mediadora cuando tiene como objetivo favorecer las estrategias comunicativas entre las partes implicadas. Al respecto afirma Ripoll-Millet (2001: 60) que el foco principal de la atención del mediador no será solo la búsqueda del acuerdo, sino examinar toda la producción de las partes (explicaciones, declaraciones, retos, preguntas) para reconocer y destacar las oportunidades de transformación que contienen. Revisar el proceso de transmisión de la información resultará determinante durante las etapas iniciales de la mediación donde se explora el conflicto, pero, lo será sin duda en las etapas posteriores de negociación y toma de decisiones, así lo indica Rondón (2012: 226) cuando explica que la comunicación es ciertamente un elemento fundamental de la negociación. El caudal, la forma y la calidad de la comunicación, así como la identidad de los que participan en el intercambio, suele influir mucho en el resultado. Por tanto, una comunicación improductiva puede conducir a la ruptura de la interacción de las partes o a la imposibilidad total de iniciar negociaciones.

La comunicación se presenta como un elemento trascendental en el proceso mediador, pero, como apunta Rondón García (2012: 59), la falta de comunicación o una comunicación inadecuada entre las partes es una de las causas fundamentales de conflicto. La mediación ha de intentar neutralizar los obstáculos que impiden el diálogo productivo sobre las cuestiones del conflicto, para que los miembros de la familia puedan negociar y redefinir las cuestiones comunes, así como elaborar nuevas formas de comunicación que puedan ser útiles para el futuro. De esta aportación se extrae la oportunidad que la mediación ofrece para las familias que tienen carencias o dificultades en sus procesos comunicativos. Si retomamos el estudio sobre los patrones comunicativos, se puede pensar que la mediación puede perfeccionar las estrategias comunicativas orientadas a la conformidad que son tendentes a la evitación de la confrontación y a la jerarquización de la toma de decisiones, además de proveer un interés por el diálogo interpersonal y subjetivo como acción para conocer la percepción contextual de los demás integrantes de la familia.

Retomando la idea del cambio y la transformación de las dinámicas internas familiares, la mediación se contempla como recurso que puede incidir en ello. En este sentido, afirman Covarrubias Terán y Gómez Herrera (2012: 250) que la búsqueda de orientaciones sobre cómo educar al niño/a se ha convertido en una necesidad para muchos/as padres-madres, lo que a la vez ha inducido a los especialistas a la producción de manuales y guías para la educación de los/as hijos/as; incluso esta orientación se ha extendido para aquéllos que aún no son padres-madres pero pronto lo serán. Así pues, dadas las características actuales de la familia mexicana del siglo XXI, con marcada intención transformadora a través de la capacitación, se puede con- 
siderar que la mediación puede brindarse como recurso social de apoyo para las familias que consideren que un recurso que les procure una mejora en sus habilidades comunicativas para la gestión de conflictos y, además, para el enfrentamiento de situaciones futuras.

\section{Conclusiones}

A través de los últimos dos siglos, la historia de México ha tenido un marcado elemento de modernidad, apertura, mestizaje y urbanización, hechos que han producido cambios políticos, sociales, culturales y económicos, siendo la familia el eje central donde estos cambios pueden verse materializados en las interacciones, planes de vida, oportunidades, composición y estructura. Los cambios percibidos en las familias mexicanas se han concentrado, principalmente, en la adjudicación y determinación de los roles en el interior de la familia, las formas de interacción entre los miembros, el ejercicio de la parentalidad y la comunicación como elemento cada vez más presente en las dinámicas rutinarias familiares como vehículo para la interacción, la transmisión de necesidades y de afectos.

Con respecto al cambio de roles o reparto equitativo de los mismos, destacando la óptica de género, si bien se han observado cambios con relación a la actividad de la mujer en el espacio público como sostén (no necesariamente único) de la familia, se destacan importantes reticencias al cambio como consecuencia de la simbología masculina (padre proveedor o jefe de familia), además de la simbología femenina (madre cuidadora). Estas reticencias hacen que, a pesar de que se percibe el cambio, éste sea más lento de lo que las condiciones socioeconómicas actuales podrían permitir a las familias, convirtiéndose en un importante reto cultural para el país.

Los roles de género van a establecer también muchos de los indicadores que componen el rol parental en el seno de la familia. La parentalidad, o relación de cuidado, educación, afectividad, protección y socialización de los progenitores con sus hijos/as es, en muchos casos, reflejo del desarrollo en las generaciones pasadas, aunque en México existe una concepción creciente de que los padres deben prepararse y planificar la parentalidad para garantizar mayor éxito. Además de la ejecución de la parentalidad, la sociedad mexicana planifica el momento de la fecundidad teniendo en cuenta, cada vez más, factores relacionados con la independencia económica y el éxito profesional que se verán condicionados por el proceso formativo, siendo éste cada vez más largo. Si bien la sociedad mexicana es joven, es importante tener en cuenta el efecto calendario que podrá determinar de forma relevante y en poco tiempo las cifras de natalidad en México. No obstante, esto puede no ser necesariamente un problema, puesto que la formación de la sociedad mexicana también incluye el interés por la educación y capacitación relacionada con el futuro ejercicio parental, además de la estabilidad económica, he- cho que muestra el cambio de concepción de las generaciones que actualmente están en edad reproductiva hacia la idea de que la familia, además de soporte económico y recursos, debe ofrecer elementos educativos, relacionales, socializadores y afectivos y de convivencia.

Así pues, bajo la premisa de que las actuales generaciones en edad reproductiva conciben como algo importante la capacitación y el acceso constante a recursos de apoyo de las dinámicas familiares, se considera la mediación como un recurso que ofrecerá un espacio donde las familias podrán gestionar sus conflictos de forma eficaz, positiva y con trascendencia futura, desde una óptica inclusiva y capacitadora conducente al bienestar individual y del conjunto familiar. Como se ha estudiado, el objetivo de la mediación es lograr que los diferentes miembros de la familia acuerden entre sí llevar a cabo un proceso de resolución de conflictos a partir de la intervención guiada de un profesional quien ayudará de una manera neutral a cada uno a definir el problema tal y como ellos mismos lo ven, a entender las opiniones e intereses de los demás y a buscar todos juntos soluciones válidas y duraderas en el tiempo. Es decir, a través de un proceso de comunicación eficaz, las partes podrán expresar y comprender las ideas propias y de los otros integrantes de la familia e incluso, se adquirirán o mejorarán las habilidades comunicativas.

Bibliografía

ALZATE SÁEZ DE HEREDIA, R. (2007): "La dinámica del conflicto", en H. Soleto y M. Otero, Mediación y solución de conflictos. Habilidades para una necesidad emergente. Madrid, Tecnos.

ALANíS ENCISO, F. S. (2005): "Regreso a casa: La repatriación de mexicanos en Estados Unidos durante la Gran Depresión, el caso de San Luis Potosí, 1929-1934", Estudios de Historia Moderna y Contemporánea de México, 29, pp. 119-148.

BLEJER, M. I.; JOHNSON, H. G. y PORZECANSKI, A. C. (1977): “Un análisis de los determinantes económicos de la Migración mexicana legal e ilegal hacia los Estados Unidos", Demografía y Economía, 11 (3), pp. 326-340.

CABRANES MÉNDEZ, F; DOMÍNGUEZ AGUILAR, M. y ORTIZ PECH, R. (2019): “Del milagro mexicano a la globalización neoliberal y su materialización en la ciudad de Mérida, México", Península, 14 (1), pp. 51-79.

CAMPOS COVARRUBIAS, G. y LULE MARTíNEZ, N. E. (2010): “Crisis, evolución mundial y sus efectos en México: Una visión desde el Observatorio Ciudadano", Xihmai, 5 (10), pp. 45-58.

CHANCE, R. H. y BUSTAMANTE, J. (1979): Las expulsiones de indocumentados mexicanos, Demografía y economía, 13 (2), pp. 185-207.

COMISIÓN EUROPEA (2002): Libro Verde sobre las modalidades alternativas de solución de conflictos en el ámbito del derecho civil y mercantil [COM (2002) 196]. Bruselas, Diario Oficial de la Comisión Europea

CONSEJO NACIONAL DE POBLACIÓN [CONAPO] (2012): 4 de Marzo, día de la Familia, México, Secretaría de Gobernación. Recuperado de: 
http://www.conapo.gob.mx/en/CONAPO/4_de_Marzo_Dia_de_la_ Familia

CORNIA, G.; JOLLY, R. y STEWART, F. (1987): Ajuste con rostro humano. Madrid, Siglo XXI Editores.

COVARRUBIAS TERÁN, M. A. y GÓMEZ HERRERA, J. (2012): “Transformación y contemporaneidad de la familia: el caso de las familias mexicanas", Revista de Psicología (Trujillo), 14 (2), pp. 244-259.

CUE MANCERA, A. (2001): "El error de diciembre y el Libro Verde", El cotidiano, 17 (105), pp. 70-79.

DEFRAIN, J. (1999): "Strong Families", Family Matters, 53, pp. 1-8.

DEFRAIN, J. y ASAY, S. M. (2007): "Strong Families Around the world", Marriage and Family Review, 41, pp. 1-10.

DEFRAIN, J. y OLSON, D. (2006): “Desafíos y fortalezas de la familia y la pareja en los Estados Unidos de América”, en R. Esteinou (ed.), Fortalezas y desafíos de las familias en dos contextos: Estados Unidos de América y México. México, Centro de Investigaciones y Estudios Superiores de Antropología Social CIESAS.

DÍAZ ARGUELLO, A. (2011): “La comunicación basada en el Buen Trato: una herramienta para educar con la familia", Revista de Educación de Extremadura REDEX, 10 (2), pp. 59-80.

ESTEINOU, R. (2010): Las relaciones de pareja en el México moderno. México, Casa del Tiempo.

ESTEINOU, R. (2004): “La parentalidad en la familia: cambios y continuidades", en M. Ariza y O. de Oliveira (coords.), Imágenes de la Familia en el cambio de Siglo. México, Universidad Nacional Autónoma de México UNAM, pp. 251-281.

FLORES GALAZ, M. M. (2011): “La cultura y las premisas de la familia mexicana", Revista Mexicana de Investigación en Psicología, 3 (2), pp. 148-153.

GARCÍA, B. y OLIVEIRA, O. (2004): "El ejercicio de la paternidad en el México Urbano", en M. Ariza y O. de Oliveira (coords.), Imágenes de la Familia en el cambio de Siglo, México, Universidad Nacional Autónoma de México UNAM, pp. 283-317.

GARZA GUZMÁN, M. R. (2014): “Antecedentes del estudio de la comunicación interpersonal", Historia y Comunicación Social, 19 (especial), pp. 315-326.

GONZALBO AIZPURU, P. (1998): "La familia en México colonial: Una historia de conflictos cotidianos", Estudios Mexicanos, 14 (2), pp. 389-406.

GORJÓN GÓMEZ, F. J. y SÁENZ LÓPEZ, K. A. C. (2013): “Los intangibles de la Mediación “, en. F. Gorjón Gómez y A. López Peláez (coords.), Estado del Arte de la Mediación. Navarra, Thomson Reuters Aranzadi.

GORJÓN GÓMEZ, F. J. y VÁZQUEZ GUTIÉRREZ, R. L. (2015): “Métodos Alternos de solución de conflictos y su protagonismo en el nuevo contexto legal mexicano, retos y perspectivas", en F. P. Arellano Hernández y P. A. Cabello Tijerina (coords), Retos y perspectivas de los MASC en México. México, Tirant Lo Blanch.

GRAMMONT, H.; LARA FLORES, S. M. y SÁNCHEZ GÓMEZ, M. J. (2004): "Migración rural temporal y configuraciones familiares, los casos de Sinaloa, México; Napa y Sonoma, EE.UU.", en M. Ariza y O. de Oliveira (coords.), Imágenes de la Familia en el cambio de Siglo. México, Universidad Nacional Autónoma de México UNAM.

GROVER DUFFY, K; GROSCH, J. K. y OLCZAK, P.V. (1996): La mediación y sus contextos de aplicación. Barcelona, Paidós.

GUTIÉRREZ CAPULÍN, R.; DÍAZ OTERO, K. Y.; ROMÁN REYES, ROSA PATRICIA. (2016): "El concepto de familia en México: una revisión desde la mirada antropológica y demográfica", Ciencia Ergo Sum, 23 (3), pp. $218-230$.

INSTITUTO NACIONAL DE ESTADÍSTICA Y GEOGRAFÍA. (2016): Encuesta Nacional sobre la Dinámica de las Relaciones en los Hogares, ENDIREH-16. Ciudad de México, INEGI.

KOERNER, A. F. y FITZPATRICK, M. A. (2002): "Toward a Theory of family communication", Communication Theory, 12 (1), pp. 70-91.

LÓPEZ ROMO, H. (2012): Los once tipos de familias en México. México, Instituto de Investigaciones Sociales.

MÁRQUEZ ALGARA, M. C. y VILLA CORTÉS, J. C. (2013): "Medios Alternos de solución de conflictos", en E. Ferrer Mac-Gregor Poissot; J.L. Ca- ballero Ochoa y C. Steiner, Derechos Humanos en la Constitución: Comentarios de jurisprudencia constitucional e interamericana. México, Universidad Nacional Autónoma de México UNAM.

MOORE, C. (1995): El proceso de Mediación. Barcelona, Granica.

PACHECO, E. y BLANCO, M. (2011): "Tiempos Históricos, contextos sociopolíticos y la vinculación familia-trabajo en México: 1959-2010", en J. Flores Dávila (coord.), A 50 años de la Cultura Cívica en honor al profesor Sidney Verba. México, Universidad Nacional Autónoma de México UNAM.

PARK, R. (1938): "Reflections on Communications and Culture”, American Journal of Sociology, 44, pp. 187-205.

PÉREZ DÍAZ, J. y ABELLÁN GARCÍA, A. (2018): “Envejecimiento demográfico y vejez en España", Panorama Social, 28, pp. 11-47.

RAMÍREZ SERRANO, L. A. (2007): El funcionamiento familiar en familias con hijos drogodependientes: un análisis etnográfico [Tesis de Doctorado, Universidad de Valencia] https://roderic.uv.es/handle/10550/15427.

REDORTA LORENTE, J. (2009): "Entorno de los Métodos Alternativos de solución de conflictos", Revista de Mediación, 2 (3), pp. 28-37.

RENDÓN, T. (2004): “El mercado laboral y la división intrafamiliar del trabajo", en M. Ariza y O. Oliveira (coords.), Imágenes de la familia en el cambio de siglo, México, Universidad Nacional Autónoma de México UNAM, pp. 49-87.

RESÉNDIZ GARCÍA, R. R. (2011): "Ciudadanía y revolución mexicana en Chiapas: 1909-1939", Revista Temas Sociológicos, 15, pp. 123-144.

RIPOLL-MILLET, A. (2001): Familias, trabajo socialy mediación, Barcelona, Paidós Ibérica.

RIZO, M. (2021): “Comunicometodología y comunicación interpersonal. Presencias y ausencias en la comunicología mexicana", Razón y Palabra, 29 [Revista Digital] http://www.razonypalabra.org.mx/N/n67/ actual/2mrizo.html.

RONDÓN GARCÍA, L. M. (2012): Bases para la mediación familiar. Valencia, Tirant Lo Blanch.

ROSALES BÁEZ, B. (2018): "Métodos alternativos de solución de conflictos", Díké, 12 (23), pp. 233-238.

SOLETO MUÑOZ, H. y OTERO PARGA, M. (2007): Mediación y solución de conflictos. Habilidades para una necesidad emergente. Madrid, Tecnos.

SUARES, M. (1996): Mediación. Conducción de disputas, comunicación y técnicas. Buenos Aires, Paidós Mediación.

VALDO GRAJALES, L. O. (2006): "Medios Alternativos de Resolución de Conflictos", en D. Cienfuegos Salgado y M. C. Macías Vázquez (coords.), Estudios en homenaje a Marcia Muñoz de Alba Medrano: Estudios de derecho público y política, México, Universidad Nacional Autónoma de México UNAM, 369-390.

VEREA CAMPOS, M. y HIERRO PERÉZCASTRO, G. (1998): Las mujeres en América del Norte al fin del Milenio. México, UNAM.

VILLALOBOS, O. (1998): Política y Gerencia de la Comunicación Social. Maracaibo, EDILUZ.

WELTI CHANES, C. (2015): ¡Qué familia! La familia en México en el siglo XXI. Encuesta nacional de la Familia. México, Universidad Nacional Autónoma de México UNAM.

WHITCHURCH, B. y DICKSON, F. (1987): "Family Communication”, en M. Sussman y S. Steinmetz (eds.), Handbook of marriage and th family. New York, Plenum. 